Araştırma Makalesi / Research Article

Elektrik Elektronik Mühendisliği /

Electrical Electronic Engineering
Iğdır Üniversitesi Fen Bilimleri Enstitüsü Dergisi, 10(1): 101-111, 2020

Journal of the Institute of Science and Technology, 10(1): 101-111, 2020

\title{
Design and Implementation of Autonomous Surface Vehicle for Inland Water
}

\section{Haluk BAYRAM ${ }^{1 *}$}

\begin{abstract}
This paper considers the design and implementation of a low-cost and modular autonomous surface robot for inland water. The design process consists of three stages: Mechanical and electro-mechanical design, electrical and electronic design and software design. The mechanical design is based on a two-hull construction because of its low risk of capsizing in rough water. Off-the-shelf hulls and electric trolling motor are preferred to reduce the cost. The robot is steered by a rudder controlled by a servo motor. A Robot Operating System based software running on an on-board computer is developed to achieve autonomy. The robot's status is monitored using the ground station software. The developed system was tested through a series of field experiments. The system is also compared with the existing designs. The robot's available deck space and modular software architecture enable users to easily integrate various sensors and mechanical parts for a wide range of applications such as environmental monitoring, surveillance and patrolling.
\end{abstract}

Keywords: Autonomous surface vehicle, autonomous robots, field robotics

\section{İç Sular İçin Otonom Suüstü Araç Tasarımı ve Uygulaması}

ÖZET: Bu makale, iç sularda çalışacak düşük maliyetli ve modüler bir otonom suüstü robotunun tasarım ve gerçeklemesini ele almaktadır. Tasarım süreci üç aşamadan oluşmaktadır: Mekanik ve elektromekanik tasarım, elektrik ve elektronik tasarım ve yazılım tasarımı. Mekanik tasarım, dalgalı zamanlarda devrilme riskinin düşük olmasından dolayı çift gövdeli yapıya dayanmaktadır. Maliyeti düşürmek için piyasada mevcut gövdeler ve elektrikli dıştan takmalı motor tercih edilmişsir. Robot, servo motor tarafından kontrol edilen dümen sayesinde yönlendirilir. Robotun otonomisini gerçeklemek için üzerindeki bilgisayarda çalışan Robot Operating System tabanlı yazılım geliştirilmiştir. Robota ait bilgiler yer istasyon yazılımı üzerinden anlık gözlemlenebilmektedir. Geliştirilen robotik sistem, bir dizi saha deneyleriyle test edilmiştir. Sistem ayrıca mevcut tasarımlar ile de karşılaştırılmıştır. Robotun geniş güverte alanına ve modüler yazılım mimarisine sahip olması kullanıcılara, çevre izleme, gözetleme ve devriye gibi çok çeşitli uygulamalar için gerekli farklı sensörleri ve mekanik parçaları sisteme kolayca entegre etmelerini sağlamaktadır.

Anahtar Kelimeler: Otonom suüstü arac1, otonom robotlar, saha robotiği

\footnotetext{
${ }^{1}$ Haluk BAYRAM (Orcid ID: 0000-0002-7883-0077), İstanbul Medeniyet University, Faculty of Engineering and Natural Sciences, Electrical and Electronics Engineering, Field Robotics Laboratory, Istanbul, Turkey

* Sorumlu Yazar/Corresponding Author: Haluk BAYRAM, e-mail: haluk.bayram@medeniyet.edu.tr 


\section{INTRODUCTION}

Autonomous robots/vehicles have the capability of effectively performing long-term, laborintensive and dangerous tasks. Autonomous surface vehicles (ASVs) have many applications ranging from civil to military purposes. Among the civil applications are environmental monitoring (Bayram et al., 2016; Hitz et al., 2017; Jung et al., 2017; Patel et al., 2019), water quality assessment (Ferri et al., 2014; Fornai et al., 2016; Hitz et al., 2012), inspection of wet nuclear storage facilities (Groves et al., 2019), bridge inspection (Murphy et al., 2011) and oceanographic research (Caccia et al., 2005). In the military domain, ASVs are used for patrolling shorelines or harbors (Wolf et al., 2017) and maritime interdiction (See, 2017). ASVs are also integrated with other types of autonomous vehicles, such as unmanned aerial vehicles (Nistico et al., 2017) and autonomous underwater vehicle (Melo and Matos, 2008).

There are many commercially available ASVs as research platforms, such as Heron (ClearPath Robotics, Ontario, Canada), SR-Surveyor (Searobotics, Stuart, FL, USA) and C-Enduro (L3 ASV, Portchester, UK). However they either are expensive or do not allow users to easily make revisions on the mechanical units and to mount additional hardware on them. Therefore, it is difficult for those who do research on ASVs to find an appropriate ASV. In this paper, we aim to design and implement a lowcost and modular ASV using off-the-shelf hulls and electro-mechanical units for inland water.

In the design of autonomous surface vehicles, two-hull based design, known as a catamaran-type of construction, is commonly used since it provides stability, ease of deck access and allows for additional mechanisms, such as a winch mechanism, to be placed centric between the hulls (Manley, 2008; Liu et al., 2016). This is the reason why we choose the two-hull design in our surface vehicle.

Single or multiple motors can be used for propulsion. In a two-motor based design, the motors are identical and fixed. The heading of an ASV is controlled by differential thrust provided by these motors. Therefore, there is no need for an additional steering mechanism. However, any performance difference between the motors makes it harder to control the robot. In a single-motor based design, this problem does not show up. But a steering mechanism is needed. Therefore, we prefer the single-motor design to avoid this problem and decrease the cost.

Since electric motors are widely used in ASVs, batteries are the main source of power. In addition, other energy sources, such as solar (González-Reolid et al., 2018) and wind (Friebe et al., 2017), are also utilized to enable long-term autonomy. The power source of our design is selected as lead-acid batteries due to their low cost and high energy density.

The design of an ASV may require special equipment depending on whether the vehicle operates in an inland water or at sea. Operation at sea differs from inland water in that a surface vehicle must comply with the marine rules, which are described in Convention on the International Regulations for Preventing Collisions at Sea (COLREGS) (Beser and Yildirim, 2018; Woerner et al., 2019). In order to operate according to these rules, the surface vehicle should be equipped with advanced active sensors, such as radar, LIDAR or sonar.

In this paper, we study the design and implementation of a low-cost and modular ASV using offthe-shelf hulls and electro-mechanical units for inland water. We proceed as follows. First, the mechanical design and electro-mechanical components are described. Secondly, the electrical and electronic system is introduced. Thirdly, the software design of the robot is explained. Then, the comparison with the existing designs is presented. After the field experiment section, the paper concludes with a summary and future directions. 


\section{Design and Implementation of Autonomous Surface Vehicle for Inland Water}

\section{MATERIALS AND METHODS}

\section{Mechanical and Electro-mechanical Design}

The robot's mechanical construction has two main parts: (i) Floating body, (ii) Propulsion and steering units. The floating body is chosen as a catamaran with two hulls. The design of the robot is shown in Figure 1.
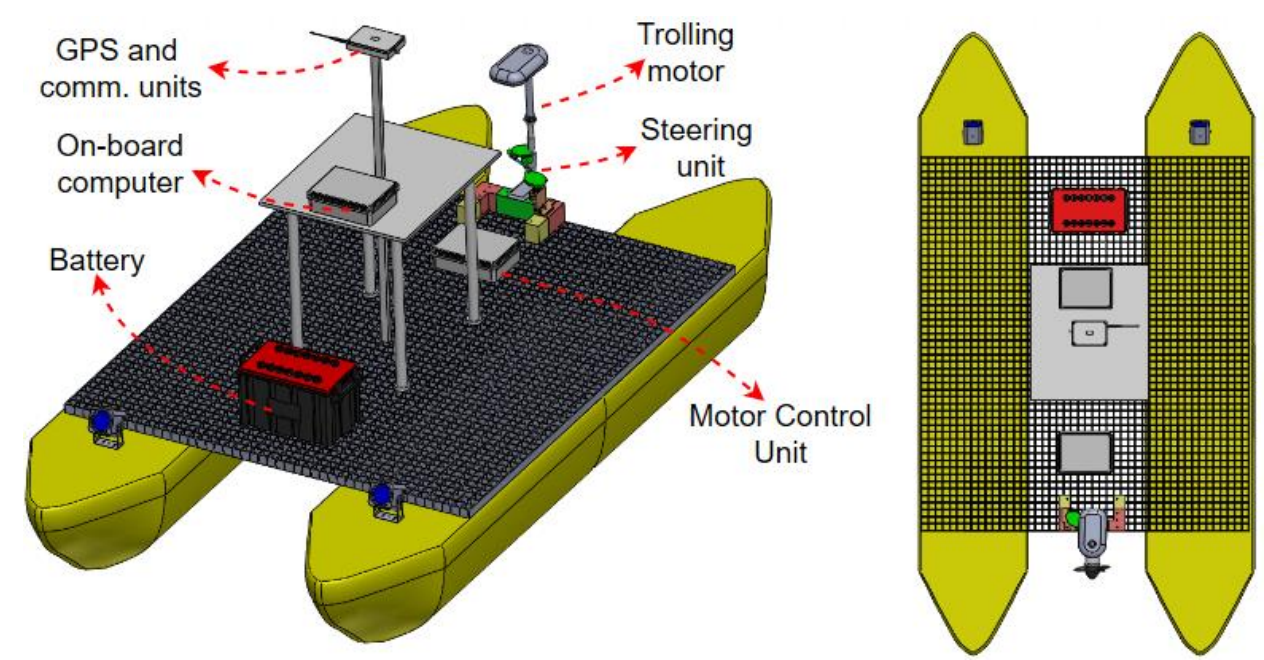

Figure 1. Design of the unmanned surface robot: Front view (left), top view (right)

To reduce the cost, the hulls are taken from an off-the-shelf rowing boat, NE336 Catamaran Rowing Boat (Martek, Izmir, Turkey), which is used for recreational purposes. The exterior of each hull is made of polyethylene. To prevent sinking when the hulls are broken, polyurethane foam is filled to the interior of the hulls. Each hull is $336 \mathrm{~cm}$ long and $35 \mathrm{~cm}$ width. The catamaran with two hulls can carry approximately a $200 \mathrm{~kg}$ payload, which was verified in the field experiments.

We choose an electric trolling motor, Haibo ET-54 (Haibo Motor, Ningbo, China), for the propulsion unit because it is light-weight and low cost. The thrust it provides is $25 \mathrm{~kg}$. It operates at 12 Volt. The maximum current it draws at the highest speed is 50 Amper.

A servo motor system with Annimos $25 \mathrm{~kg}$ Digital Servo (Dsservo, Dongguan, China), is designed and manufactured using a 3D printer. The servo system is used to steer the trolling motor. The stall torque of the servo is $21 \mathrm{kgcm}^{-1}$ at 5 Volt operating voltage. The maximum steering angle is set to \pm 30 degrees because of the mechanical restrictions.

\section{Electrical and Electronic Design}

The electrical and electronic system consists of the following components: An on-board computer, two microcontroller cards, custom designed speed control circuit, servo control circuit, sensors (Attitude and Heading Reference System - AHRS, Global Positioning System - GPS, water sampling), remotecontrol (RC) receiver and two lead acid batteries. While the battery with higher energy density is used for the trolling motor, the one with low energy density is to power up the on-board computer and other electronic components. Although LiPo batteries provide better weight-energy density ratio, we prefer lead acid batteries as the power source of the system due to their low cost. The connection of these components can be seen in Figure 2. 


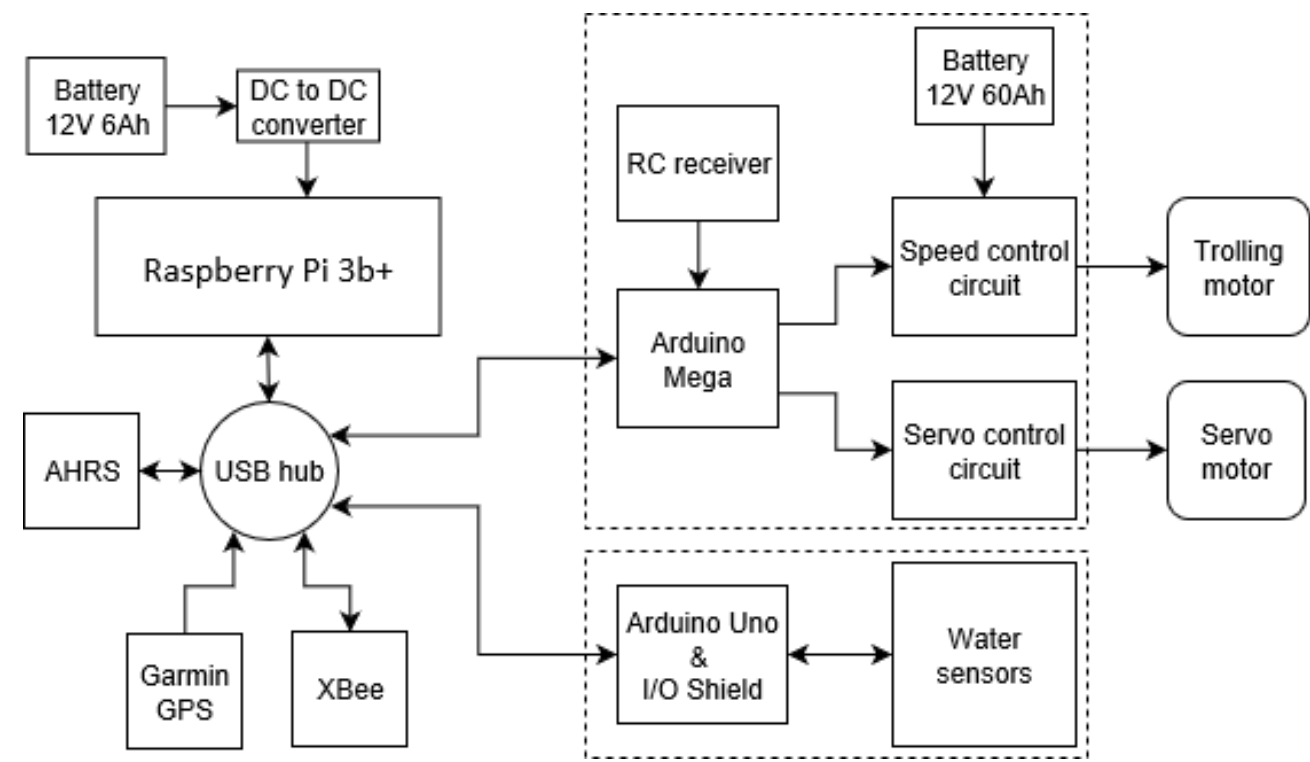

Figure 2. Connection of the electrical, electronic and electro-mechanical components

The electric trolling motor has five speed levels for forward direction and two for backward direction. The speed level is controlled by hand in the original version of the motor. Since we need to control the speed via a computer, we design a speed control circuit (Figure 2), which takes eight digital signals from the Arduino Mega card to determine the speed level and two inputs from the 12 Volt $60 \mathrm{Ah}$ battery (Mutlu, Istanbul, Turkey) to provide power to the trolling motor, and has four output lines for the motor. The servo motor used for steering the trolling motor is controlled via a pulse-width modulation (PWM) signal sent by the Arduino Mega.

The robot can operate at two different modes: Autonomous and remote-control. In the autonomous mode, the robot is controlled by a Robot Operating System (ROS) based software running on its own on-board computer. Whereas, in the remote-control mode, a user can drive the robot using a remote controller, Radiolink AT9S (Radiolink Electronics, Guangdong, China). The user can choose one of these two modes via a switch on the remote controller. The commands sent by the remote controller are received by the $\mathrm{RC}$ receiver on the boat, which is connected to the Arduino Mega. In case of any failure in the software, the user can override the software and take control of the robot.

Raspberry Pi 3 B+ (Raspberry Pi Foundation, UK) is chosen as an on-board computer for the system due to its low cost and low power consumption. The computer is powered by a 12 Volt $6 \mathrm{Ah}$ battery. The software running on the computer sends relevant commands to the Arduino cards and receives data from them over USB. Even though the computer has a built-in WiFi module, it is not suitable for a long-range communication. Therefore, we integrated an XBee Pro module (Digi, Hopkins, MN, USA) into the system, which has a maximum range of 3000 meters line-of-sight. To monitor the robot's internal states, the computer communicates with the ground station computer via the XBee module over RF communication.

An AHRS module, UM7 orientation sensor (Redshift Labs, Orem, UT, USA), is connected to the on-board computer. It contains a three-axis accelerometer, rate gyro, and magnetometer sensors. It has an extended Kalman filter (EKF) to combine all the data coming from these sensors to provide attitude and heading estimates. Its heading precision is about \pm 3 degrees. A GPS sensor, Garmin 18X (Garmin, Olathe, KS, USA), provides the global position with the robot. It has a 5-meter localization precision depending on weather and proximity to the ground. The heading and GPS position estimates coming from these sensors are used as inputs to the autonomous waypoint navigation module, which will be described in the next section. 


\section{Design and Implementation of Autonomous Surface Vehicle for Inland Water}

\section{Software Design}

We aim to build an easily customizable software infrastructure, whose core modules are available as open-source software. To achieve this aim, we choose Linux as an operation system for our on-board computer and Robot Operating System (ROS) as our software framework to develop the required software modules.

The on-board computer has an Ubuntu 16.04 Linux operating system (Canonical Group Limited, London, UK), which is installed from an Ubuntu image (Anonymous, 2018). The system has Robot Operating System Kinetic (Open Source Robotics Foundation, Mountain View, CA, USA) running on the Ubuntu 16.04.

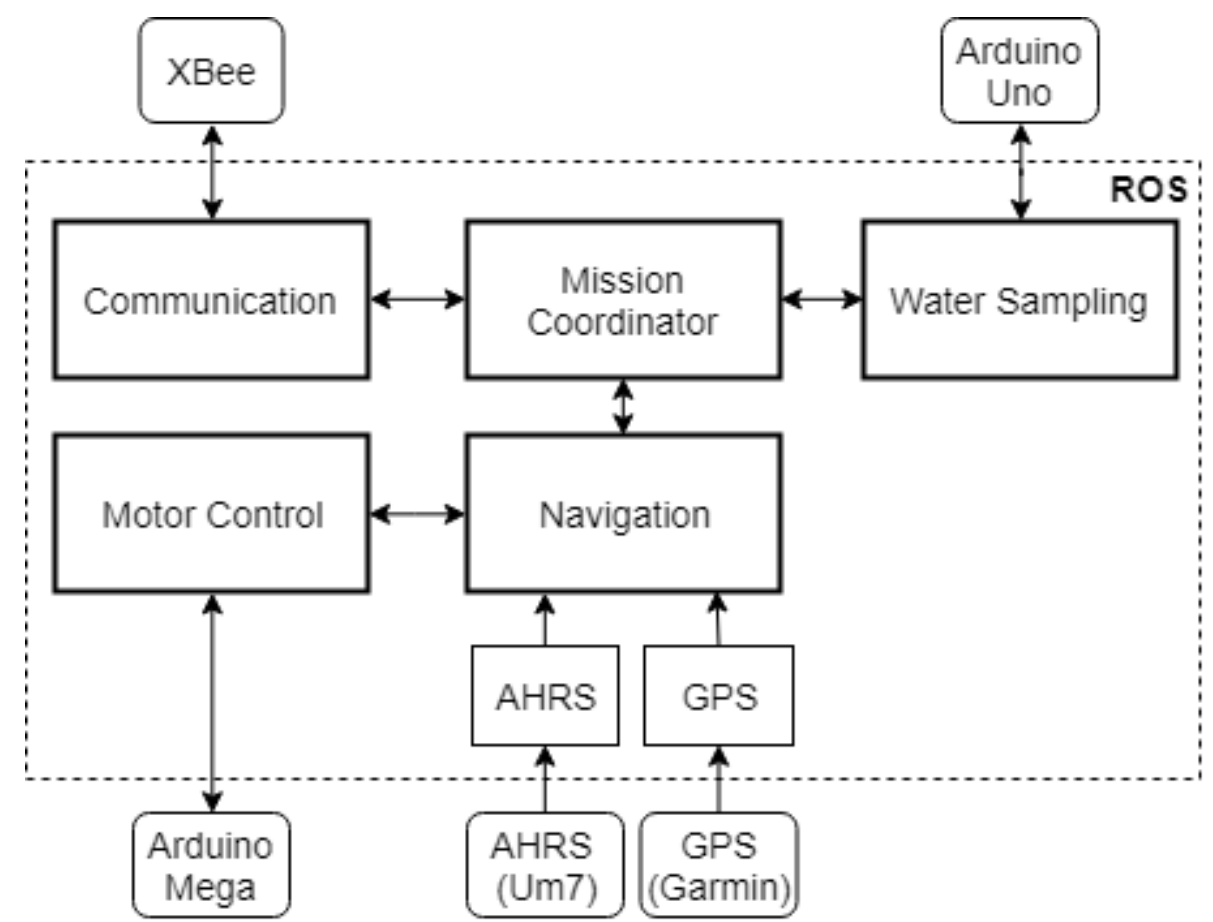

Figure 3. ROS based software architecture. While bold rectangles represent the ROS nodes developed in this work, other two rectangles denote the nodes available as a ROS package. The devices connected to the computer are shown by rounded rectangles.

We designed and developed a custom ROS software implementing the autonomous waypoint navigation, communication and other task related missions. The ROS based software has seven nodes as shown in Figure 3. We developed the following ROS nodes except AHRS and GPS nodes, which are available as a ROS package in ROS repositories.

- Communication Node: This node is responsible for sending messages to the ground station and receiving messages from the ground station over the XBee module.

- AHRS Node: This node gets the current heading estimate from the AHRS module. The node is available as a ROS package (Purvis and Brown, 2017).

- GPS Node: This node receives the robot's current GPS position from the Garmin GPS module. This node is available as a ROS package (Tossell and Thomson, 2013).

- Mission Coordinator Node: This node coordinates the mission which requires user-defined tasks (such as autonomous waypoint navigation, water sampling, video recording) to be done in a predefined order. The mission can be only autonomous waypoint navigation in which the user sends the GPS coordinates of the waypoints to the robot via the ground station and the robot navigates autonomously to them in the given order. In addition to the autonomous navigation 
mission, the user can also define additional tasks which will be done when the robot reaches the associated waypoint. In our case, this additional task is water sampling. When the robot reaches the given waypoint, it takes measurement of the water parameters (temperature, $\mathrm{pH}$, dissolved oxygen, conductivity and oxidation-reduction potential) through its water sampling sensors.

- Navigation Node: This node is responsible for autonomous waypoint navigation. It takes the currect GPS position from the GPS node, the current heading from the AHRS node and the desired GPS position. In turn, it sends the velocity and the steering angle commands to the motor control node. A PD controller (Figure 4) is implemented to steer the rudder in order to navigate to a goal GPS position. The control input to the rudder angle calculation is given in Equation 1 .

$$
u=K_{p} \theta_{e r r}+K_{d} \frac{d}{d t} \theta_{e r r}
$$

where $K_{p}$ and $K_{d}$ are the parameters of the PD controller and set to 15 and 1.5 , respectively. $\theta_{\text {err }}$ is defined as the error between the current heading $\theta$ and the desired heading $\theta^{*}$. The current heading $\theta$ is obtained from the AHRS. The desired heading $\theta^{*}$ is calculated using the desired position $\left[x^{*} y^{*}\right]^{T}$ and the current position $\left[\begin{array}{ll}x y & y\end{array}\right]^{T}$. These positions are obtained by converting GPS coordinates to local Cartesian coordinates in order to make the trigonometric and other calculations easier.

- Motor Control Node: This node transmits the speed and steering angle commands to the Arduino Mega, which in turn sends the relevant signals to the speed and servo control circuits.

- Water Sampling Node: This node is responsible for gathering water related data from the water sampling sensors through the Arduino Uno.

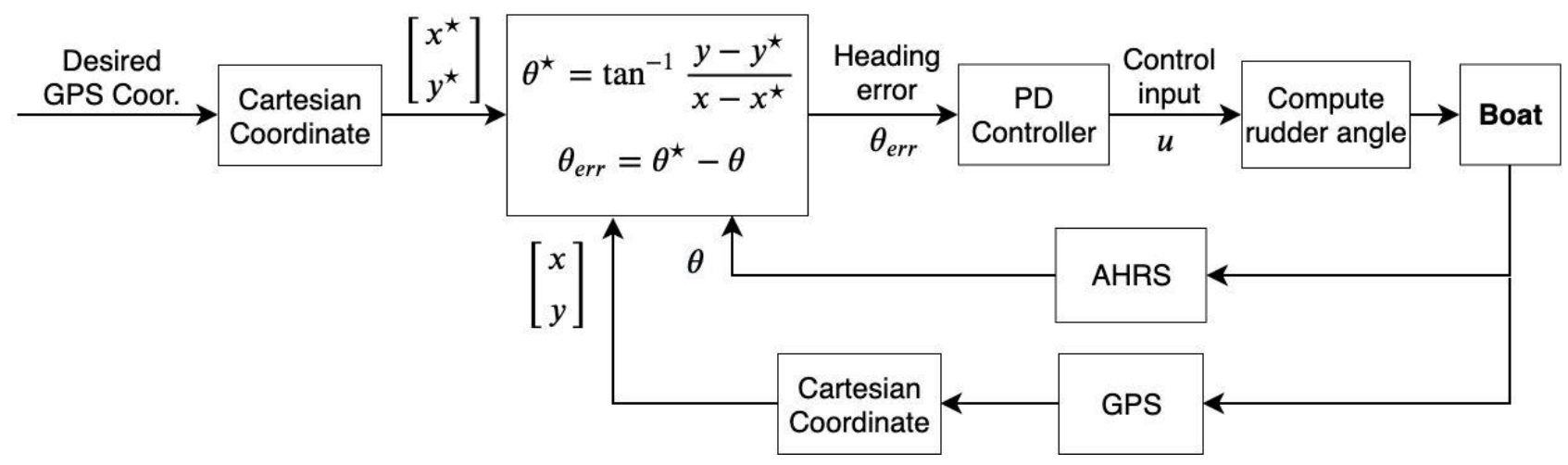

Figure 4. PD controller for steering the rudder

A ground station software (Figure 5) was developed using Python and JavaScript. The user can monitor the robot's status (battery level, current GPS location, current state, distance to the goal location, heading) and send the robot the GPS location list to be visited. The user can also track the robot on the Google-map based interface. 


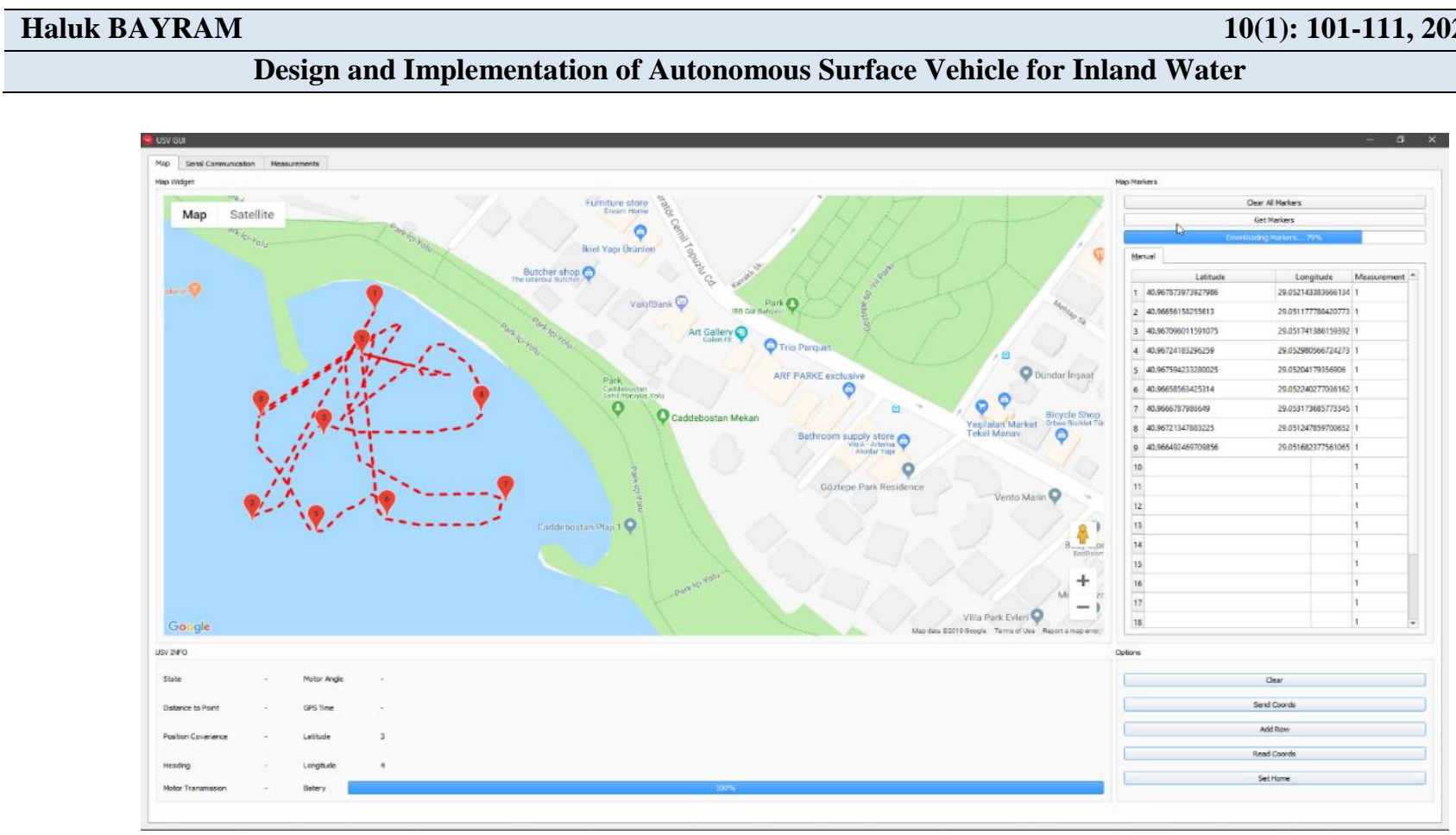

Figure 5. Ground station software

\section{RESULTS AND DISCUSSION}

\section{Comparison with Existing ASV Designs}

We compare our design with the previous works based on the following criteria: Type of construction, floating body, dimension, customizability, operation environment, weight, extra payload, autonomy, propulsion unit, power supply for the propulsion, maximum speed, operation duration and cost. According to the comparison given in Table 1, the main advantage of our design over the others is that it has the lowest cost and allows users to mount additional mechanical and/or electronic hardware on the robot's deck. The deck is a grid-like plane. Therefore, it is easy to add new parts to the deck or remove any part from it.

Table 1. Comparison with other ASV designs

\begin{tabular}{ccc}
\hline & & ASV DESIGNS \\
\hline (Moulton et al., & (Hitz et al., 2011; & (Curcio et al., \\
2018) & Hitz et al. 2012) & 2005)
\end{tabular}

(Murphy et al., $\quad$ Our ASV
2011; Steimle and
Hall, 2006;

Lindemuth et al. 2011)

\begin{tabular}{llllll}
\hline Type of Construction & Mono hull & Catamaran & Mono hull & Catamaran & Catamaran \\
\hline Floating Body & Off-the-shelf & Custom & Off-the-shelf & Custom & Off-the-shelf \\
\hline Dimension & $3.6 \mathrm{~m}$ length & $\begin{array}{l}2.5 \mathrm{~m} \text { length } \& 1.8 \mathrm{~m} \\
\text { width }\end{array}$ & $3 \mathrm{~m}$ length & $\begin{array}{l}1.9 \mathrm{~m} \text { length } \& 1.2 \\
\text { m width }\end{array}$ & $\begin{array}{l}3.4 \mathrm{~m} \text { length } \& \\
1.8 \mathrm{~m} \text { width }\end{array}$ \\
\hline Customizability & Not easy & Not easy & Not easy & Not easy & Easy \\
\hline Operation Environment & Inland water & Inland water & Sea & Sea/Inland water & Inland water \\
\hline Weight & $90 \mathrm{~kg}$ & $130 \mathrm{~kg}$ & $80 \mathrm{~kg}$ & $147 \mathrm{~kg}$ & $90 \mathrm{~kg}$ \\
\hline Extra Payload & $70 \mathrm{~kg}$ & $200 \mathrm{~kg}$ & N/A & N/A & $200 \mathrm{~kg}$ \\
\hline Autonomy & Commercial & $\begin{array}{l}\text { ROS based } \\
\text { autopilot }+ \text { ROS } \\
\text { based software }\end{array}$ & $\begin{array}{l}\text { Custom } \\
\text { software }\end{array}$ & N/A & ROS based \\
software
\end{tabular}


The bill of materials of our design is given in Table 2. Although the most expensive part of the robot is its floating body, if we manufactured this part, the cost would exceed the current cost. Furthermore, manufacturing such a part may require a special process depending on the material of which the boat is made.

Table 2. Bill of materials

\begin{tabular}{|c|c|c|c|c|}
\hline Material & Description & Qty & Price Per & Cost \\
\hline Hull & $\begin{array}{l}\text { NE336 Rowing Boat (Martek, Izmir, } \\
\text { Turkey) }\end{array}$ & 2 & $\$ 445$ & $\$ 890$ \\
\hline Trolling motor & Haibo ET-54 (Haibo Motor, Ningbo, China) & 1 & $\$ 265$ & $\$ 265$ \\
\hline Servo motor & $\begin{array}{l}\text { ANNIMOS } 25 \mathrm{Kg} \text { Digital Servo (Dsservo, } \\
\text { Dongguan, China) }\end{array}$ & 1 & $\$ 25$ & $\$ 25$ \\
\hline Flament for 3D printer & ABS flament & 2 & $\$ 15$ & $\$ 30$ \\
\hline Battery 12V 60Ah & $\begin{array}{l}\text { 12V 60Ah Full Energy (Mutlu, Istanbul, } \\
\text { Turkey) }\end{array}$ & 1 & $\$ 75$ & $\$ 75$ \\
\hline Battery $126 \mathrm{Ah}$ & Ttech 12V 6Ah (Tesan, Istanbul, Turkey) & 1 & $\$ 15$ & $\$ 15$ \\
\hline AHRS sensor & $\begin{array}{l}\text { UM7 Orientation Sensor (Redshift Labs, } \\
\text { Orem, UT, USA) }\end{array}$ & 1 & $\$ 200$ & $\$ 200$ \\
\hline GPS sensor & $\begin{array}{l}\text { Garmin GPS 18X (Garmin, Olathe, KS, } \\
\text { USA) }\end{array}$ & 1 & $\$ 160$ & $\$ 160$ \\
\hline RF communication & $\begin{array}{l}\text { XBee Pro S2C + antenna (Digi, Hopkins, } \\
\text { MN, USA) }\end{array}$ & 2 & $\$ 40$ & $\$ 80$ \\
\hline Microcontroller & Arduino Mega 2560 & 1 & $\$ 10$ & $\$ 10$ \\
\hline On-board computer & $\begin{array}{l}\text { Raspberry Pi } 3 \text { B+ (Raspberry Pi } \\
\text { Foundation, UK) }\end{array}$ & 1 & $\$ 45$ & $\$ 45$ \\
\hline SD Card & $\begin{array}{l}\text { Sandisk Ultra Plus } 64 \text { GB (SanDisk, } \\
\text { Milpitas, California, USA) }\end{array}$ & 1 & $\$ 20$ & $\$ 20$ \\
\hline Remote controller & $\begin{array}{l}\text { Radiolink AT9S (Radiolink Electronics, } \\
\text { Guangdong, China) }\end{array}$ & 1 & $\$ 210$ & $\$ 210$ \\
\hline \multirow[t]{2}{*}{$\begin{array}{l}\text { Other electrical and mechanical } \\
\text { parts }\end{array}$} & $\begin{array}{l}\text { Plastic enclosure boxes, cables, connectors, } \\
\text { screws etc. }\end{array}$ & 1 & $\$ 150$ & $\$ 150$ \\
\hline & & & Total & $\$ 2175$ \\
\hline
\end{tabular}

\section{Field Experiments}

We conducted a series of field experiments at the two different sites in order to evaluate the system performance. The first field trial was done in March 9th, 2019 at Caddebostan beach, Istanbul, Turkey. In this trial, the steering mechanism and the manual mode were tested. We also tested the payload that the robot can handle. After adding an extra payload (approximately $200 \mathrm{~kg}$ ) to the robot, we drove the robot at varying speed levels by using the remote controller. The steering mechanism and the propulsion unit handled such an extra payload.

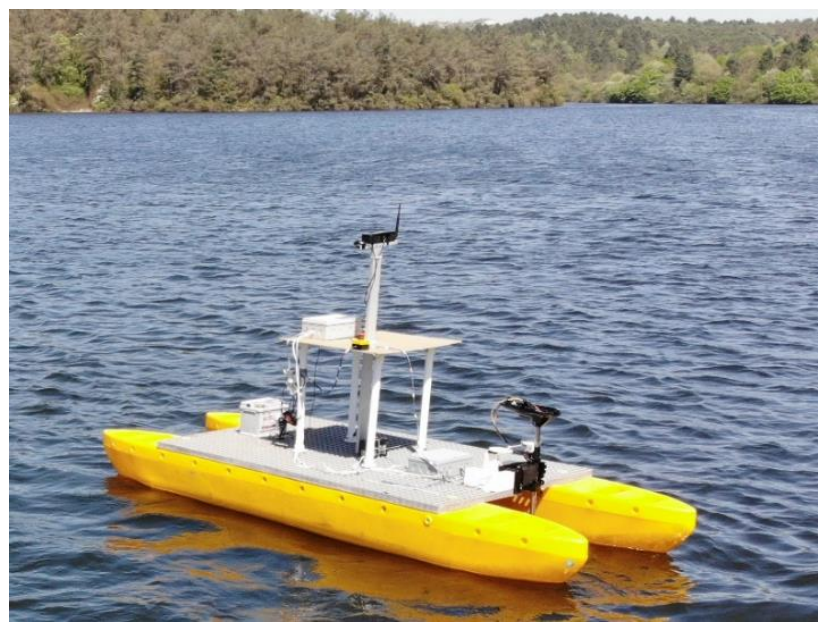

Figure 6. Footage from the field experiments in Elmali Dam, Istanbul, Turkey 


\begin{tabular}{|c|c|}
\hline Haluk BAYRAM & $10(1): 101-111,2020$ \\
\hline Design and Implementation of Autonomous Surface Vehicle for Inland Water
\end{tabular}

The second field experiment was conducted in April 30th, 2019 in Elmali Dam, Istanbul, Turkey. We tested all the system modules and the autonomous mode. A picture from the field trials can be seen in Figure 6. The robot navigated autonomously to the goal GPS locations. In a sample scenario, the robot began from the depot location, navigated to the three waypoints, and then returned the depot. The distance threshold which determines whether the distance between the robot and the goal waypoint is sufficient for a successful navigation was set to 5 meters. The average speed was about $1 \mathrm{~m} \mathrm{sec}^{-1}$. The trajectory the robot followed is shown in Figure 7. (Note that some portion of the robot's trajectory seems to be outside of water in Figure 7. But in the experiment day, the water level of the dam was higher than when the Google-maps took the picture of the dam.) It is observed that the robot sometimes made a small deviation along the way to the goal. This happened because it was windy, and the dam was choppy in the experiment day. However, the controller immediately corrected the robot's heading.

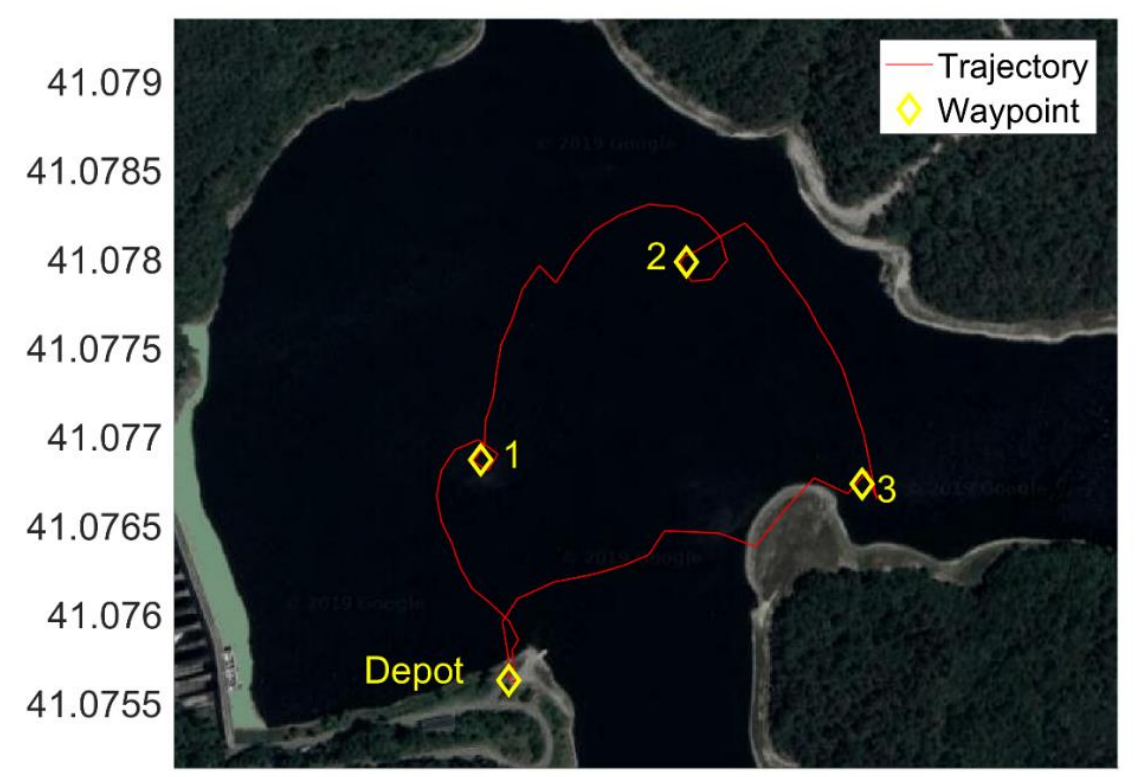

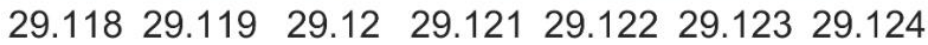

Figure 7. A sample trajectory from the field experiments in Elmali Dam, Istanbul, Turkey. The robot starts from the depot location, navigates to the waypoints (denoted by yellow diamond markers), and

finally returns to the depot. The red line represents the robot's trajectory.

\section{CONCLUSION}

In this paper, we consider the design and implementation of a low-cost and modular autonomous surface robot for inland water. The two-hull construction is chosen due to its low risk of capsizing. To decrease the cost, off-the-shelf hulls and electric trolling motor are used in the system. The robot is steered by a rudder controlled by a servo motor. The autonomy is achieved by a ROS based software running on an on-board computer. The ground station software is developed to monitor the robot's state. The developed system was tested through a series of field experiments. The system is also compared with the existing designs. This comparison reveals that our design is a low-cost design and allows users to add extra hardware on the robot's deck.

As part of future work, we will consider two extensions. First, LIDAR, ultrasound or vision sensors will be integrated into the system in order to map the environment and avoid dynamic obstacles. Secondly, we will develop informative path planning algorithms to determine measurement locations for water quality monitoring in which the developed ASV will be used as an experimental platform. 


\section{ACKNOWLEDGEMENTS}

We are grateful for the financial and logistical support of ENARGE and the contribution of Ali Akdemir, M. S. Aydogan, K. Caliskan and A. Gurses to the ground station software, mechanical design, speed control circuit, and electrical design, respectively.

\section{REFERENCES}

Anonymous, 2018. Raspberry Pi Images. http://downloads.ubiquityrobotics.com/pi.html (Date of access: 10 July 2019)

Bayram H, Hook JV, Isler V, 2016. Gathering bearing data for target localization. IEEE Robotics and Automation Letters, 1(1): 369-374.

Beser F, Yildirim T, 2018. COLREGS Based Path Planning and Bearing Only Obstacle Avoidance for Autonomous Unmanned Surface Vehicles. Procedia Computer Science, 131: 633-640.

Caccia M, Bono R, Bruzzone G, Spirandelli E, Veruggio G, Stortini AM, Capodaglio G, 2005. Sampling sea surfaces with SESAMO: an autonomous craft for the study of sea-air interactions. IEEE Robotics \& Automation Magazine, 12(3): 95-105.

Curcio J, Leonard J, Patrikalakisi A, 2005. SCOUT-a low cost autonomous surface platform for research in cooperative autonomy. IEEE OCEANS, Brest, June 20-23, 2005, pp: 725-729.

Ferri G, Manzi A, Fornai F, Ciuchi F, Laschi C, 2014. The HydroNet ASV, a small-sized autonomous catamaran for real-time monitoring of water quality: From design to missions at sea. IEEE Journal of Oceanic Engineering, 40(3): 710-726.

Fornai F, Ferri G, Manzi A, Ciuchi F, Bartaloni F, Laschi C, 2016. An autonomous water monitoring and sampling system for small-sized ASVs. IEEE Journal of Oceanic Engineering, 42(1): 5-12.

Friebe A, Olsson M, Le Gallic M, Springett JL, Dahl K, Waller M, 2017. A marine research ASV utilizing wind and solar power. IEEE OCEANS, Aberdeen, June 19-22, 2017, pp: 1-7.

González-Reolid I, Molina-Molina J, Guerrero-González A, Ortiz F, Alonso D, 2018. An Autonomous SolarPowered Marine Robotic Observatory for Permanent Monitoring of Large Areas of Shallow Water. Sensors, 18(10): 1-24.

Groves K, West A, Gornicki K, Watson S, Carrasco J, Lennox B, 2019. MallARD: An Autonomous Aquatic Surface Vehicle for Inspection and Monitoring of Wet Nuclear Storage Facilities. Robotics, 8(2): 1-17.

Hitz G, Pomerleau F, Garneau M, Pradalier C, Posch T, Pernthaler J, Siegwart RY, 2011. Lizhbeth: Toward Autonomous Toxic Algae Bloom Monitoring. IEEE/RJS International Conference on Intelligent Robots and Systems - Workshop Robotics for Environmental Monitoring, San Francisco, CA, USA, 2011, pp: 15.

Hitz G, Pomerleau F, Garneau ME, Pradalier C, Posch T, Pernthaler J, Siegwart RY, 2012. Autonomous inland water monitoring: Design and application of a surface vessel. IEEE Robotics \& Automation Magazine, 19(1): 62-72.

Hitz G, Galceran E, Garneau M, Pomerleau F, Siegwart R, 2017. Adaptive continuous-space informative path planning for online environmental monitoring. Journal of Field Robotics, 34(8): 1427-1449.

Jung S, Cho H, Kim D, Kim K, Han J, Myung H, 2017. Development of algal bloom removal system using unmanned aerial vehicle and surface vehicle. IEEE Access, 5, 22166-22176.

Lindemuth M, Murphy R, Steimle E, Armitage W, Dreger K, Elliot T, Hall M, Kalyadin D, Kramer J, Palankar M, Pratt K, 2011.Sea robot-assisted inspection. IEEE Robotics \& Automation Magazine, 18(2): 96-107.

Liu Z, Zhang Y, Yu X, Yuan C, 2016. Unmanned surface vehicles: An overview of developments and challenges. Annual Reviews in Control, 41, 71-93.

Manley JE, 2008. Unmanned surface vehicles, 15 years of development. IEEE OCEANS, Quebec City, September 15-18, 2008, pp: 1-4.

Melo J, Matos A, 2008. Guidance and control of an ASV in AUV tracking operations. IEEE OCEANS, Quebec City, 2008, September 15-18, pp: 1-7. 
Moulton J, Karapetyan N, Bukhsbaum S, McKinney C, Malebary S, Sophocleous G, Li AQ, Rekleitis I, 2018. An Autonomous Surface Vehicle for Long Term Operations. IEEE OCEANS, Charleston, October 22-25, 2018, pp: 1-10.

Murphy RR, Steimle E, Hall M, Lindemuth M, Trejo D, Hurlebaus S, Medina-Cetina Z, Slocum D, 2011. RobotAssisted Bridge Inspection. Journal of Intelligent and Robotic Systems, 64(1): 77-95.

Nisticò A, Baglietto M, Simetti E, Casalino G, Sperindè A,2017. Marea project: UAV landing procedure on a moving and floating platform. IEEE OCEANS, Anchorage, Alaska, September 18-21, 2017, pp: 1-10.

Patel M, Jernigan S, Richardson R, Ferguson S, Buckner G, 2019. Autonomous Robotics for Identification and Management of Invasive Aquatic Plant Species. Applied Sciences, 9(12): 1-21.

Purvis M, Brown A, 2017. um7. http://wiki.ros.org/um7 (Date of access: 10 July 2019)

See HA, 2017. Coordinated guidance strategy for multiple USVs during maritime interdiction operations. Naval Postgraduate School Systems Engineering, Master Thesis.

Steimle ET, Hall ML, 2006. Unmanned surface vehicles as environmental monitoring and assessment tools. IEEE OCEANS, Singapore, May 16-19, 2006, pp: 1-5.

Tossell K, Thomson R, 2013. gpsd_client. http://wiki.ros.org/gpsd_client (Date of access: 10 July 2019)

Woerner K, Benjamin MR, Novitzky M, Leonard JJ, 2019. Quantifying protocol evaluation for autonomous collision avoidance. Autonomous Robots, 43(4): 967-991.

Wolf MT, Rahmani A, Croix JDL, Woodward G, Hook JV, Brown D, Schaffer S, Lim C, Bailey P, Tepsuporn S, Pomerantz M, 2017. CARACaS multi-agent maritime autonomy for unmanned surface vehicles in the Swarm II harbor patrol demonstration. Proceedings of SPIE 10195 Unmanned Systems Technology XIX, Anaheim, California, April 9-13, 2017, pp: 101950. 